\title{
The division of labour, worker organisation, and technological change
}

Citation for published version (APA):

Borghans, L., \& ter Weel, B. J. (2005). The division of labour, worker organisation, and technological change. UNU-MERIT, Maastricht Economic and Social Research and Training Centre on Innovation and Technology. MERIT-Infonomics Research Memorandum Series No. 023 https://doi.org/10.26481/umamer.2005023

Document status and date:

Published: 01/01/2005

DOI:

10.26481/umamer.2005023

Document Version:

Publisher's PDF, also known as Version of record

\section{Please check the document version of this publication:}

- A submitted manuscript is the version of the article upon submission and before peer-review. There can be important differences between the submitted version and the official published version of record.

People interested in the research are advised to contact the author for the final version of the publication, or visit the DOI to the publisher's website.

- The final author version and the galley proof are versions of the publication after peer review.

- The final published version features the final layout of the paper including the volume, issue and page numbers.

Link to publication

\footnotetext{
General rights rights.

- You may freely distribute the URL identifying the publication in the public portal. please follow below link for the End User Agreement:

www.umlib.nl/taverne-license

Take down policy

If you believe that this document breaches copyright please contact us at:

repository@maastrichtuniversity.nl

providing details and we will investigate your claim.
}

Copyright and moral rights for the publications made accessible in the public portal are retained by the authors and/or other copyright owners and it is a condition of accessing publications that users recognise and abide by the legal requirements associated with these

- Users may download and print one copy of any publication from the public portal for the purpose of private study or research.

- You may not further distribute the material or use it for any profit-making activity or commercial gain

If the publication is distributed under the terms of Article $25 \mathrm{fa}$ of the Dutch Copyright Act, indicated by the "Taverne" license above, 


\section{MERIT-Infonomics Research Memorandum series}

The Division of Labour, Worker Organisation, and Technological Change

\section{Lex Borghans \& Bas ter Weel}

\section{5-023}

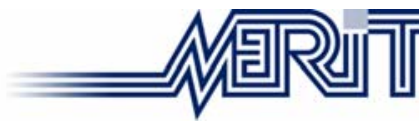

MERIT - Maastricht Economic Research Institute on Innovation and Technology

\section{PO Box 616}

6200 MD Maastricht

The Netherlands

T: +31433883875

F: +31433884905

http://www.merit.unimaas.nl

e-mail:secr-merit@merit.unimaas.nl

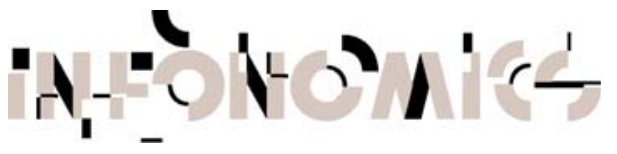

International Institute of Infonomics

c/o Maastricht University PO Box 616

6200 MD Maastricht

The Netherlands

T: +31433883875

F: +31453884905

http://www.infonomics.nl

e-mail: secr@infonomics.nl 


\title{
The Division of Labour, Worker Organisation, and Technological Change*
}

\author{
Lex Borghans \\ ROA, Maastricht University \\ Maastricht, the Netherlands \\ l.borghans@roa.unimaas.nl
}

\author{
Bas ter Weel \\ MERIT, Maastricht University \\ Maastricht, the Netherlands \\ b.terweel@merit.unimaas.nl
}

August 2005

\begin{abstract}
The model developed in this paper explains differences in the division of labour across firms as a result of computer technology adoption. We find that changes in the division of labour can result both from reduced production time and from improved communication possibilities. The first shifts the division of labour towards a more generic structure, while the latter enhances specialisation. Although there exists heterogeneity, our estimates for a representative sample of Dutch establishments in the period 1990-1996 suggest that productivity gains have been the main determinant for shifts in the division of labour within most firms. These productivity gains have induced skill upgrading, while in firms gaining mainly from improved communication possibilities specialisation increased and skill requirements have fallen.
\end{abstract}

Keywords: Division of labour, Wage level and structure; Technological change; Computerisation of the labour market

JEL Classification: J31; O15; O33

\footnotetext{
${ }^{*}$ We wish to thank David Autor, Eve Caroli, Frank Cörvers, Paul David, Andries de Grip, Stephen Machin, Luc Soete, Alexandra Spitz, Bas Straathof, Gerard van den Berg, John Van Reenen, Adriaan van Zon and seminar participants at the Dutch Central Bank, the MERIT Workshop on "IT and Industry and Labour Market Dynamics" and the 4th ZEW Conference on the "Economics of Information and Communication Technologies" for helpful comments and discussions. We thank the Institute for Labour Studies (OSA) for making available the data used in this paper and for financial support. Bas ter Weel also acknowledges financial support from the Netherlands Organisation for Scientific Research (NWO).
} 


\section{Introduction}

The rapid spread of computer technology has led to substantial changes in the division of labour and a shift in the demand for labour in favour of skilled workers. Mostly these changes have been accompanied by flatter organisational structures, larger autonomy for workers or workgroups, the application of innovative human resource management practices, and so on. There are also less typical examples where computerisation is associated with increased specialisation (e.g., the rapid increase of call-centers), scripting of communication with clients and stricter procedures. Although the empirical relationship between information and communication technology (ICT) adoption and organisational change has been well-documented, disagreement remains about the reasons why computerisation provides firms with incentives to change the structure of their organisation and the skill requirements of their workforce.

One class of explanations thinks about organisational change as an innovation. Computer technology (especially "organisational computing") provides non-trivial possibilities for the development of new services that also require other forms of cooperation between workers (e.g., Bresnahan, 1999) and as computers become cheaper and more powerful, the business value of the pure production process decreases, while managers can make a difference by making better use of the scarcer manpower (e.g., Brynjolfsson and Hitt, 2000 for an overview). In this view human resource management practices in the highperformance workplace play a crucial role in improving performance and originate from the increased marginal value of improvements in the way workers cooperate. ${ }^{1}$ Such organisational innovations require innovative managers and an adaptable workforce that does not resist changes, so observed differences in the behaviour and performance of firms reflect differences in their success to deal with the new opportunities.

Others think about the effects of computer technology on the production process in terms of changes in marginal benefits and marginal costs. Computerisation has changed the relative value of skills, lowering the value of routine cognitive and manual tasks and increasing the value of non-routine cognitive and interactive tasks (e.g., Autor et al., 2003 and Spitz, 2003). To relate shifts in costs and benefits to organisational change, considerations regarding the organisational structure have to be taken into account. In

\footnotetext{
${ }^{1}$ See e.g., the industry studies by Ichniowski et al. (1997) and Ichniowski et al. (2003), and the work by Black and Lynch (2001; 2004) for the United States.
} 
a case-study Autor et al. (2002) investigate how a large bank re-optimises the organisational procedures reacting to the possibilities offered by new technology. A possible interpretation of this process is that computer technology affects the classical trade-off between the division of labour and communication costs, as studied by Becker and Murphy (1992), Radner (1993), and Bolton and Dewatripont (1994). ${ }^{2}$ Without denying the potential for innovation that can be associated with the recent computer revolution, when the trade-off between the benefits of specialisation and the costs of communication determines the division of labour, it is hard to imagine that computers did not affect the division of labour. Yet, both increased productivity in separate tasks and increased efficiency of communication will affect the benefits of specialisation and communication costs.

The aim of this paper is to examine how far one can go toward explaining changes in the division of labour that recently occurred in relation to computer adoption using a simple framework about the cost and benefits of specialisation. We develop a model in which a density function of a continuum of tasks represents the work that has to be carried out to produce output. Different types of workers are described by the time they need to carry out each of these tasks. In addition to production time, workers spend time communicating to coordinate activities. The way in which a firm assigns tasks to workers yields the division of labour within the firm. In this setting, on the one hand, a more extensive division of labour raises productivity because the returns to time spent on tasks are generally greater to workers who concentrate on a narrower range of tasks. On the other hand, a more generic division of labour minimises the costs of coordinating tasks between workers and may increase productivity as well. The optimal division of labour depends on the trade-off between the benefits from specialisation and the costs of communication or coordination.

The adoption of computer technology can be beneficial in (i) supporting the workers to carry out tasks more rapidly and in (ii) communicating more effectively. We show that both forms of increased productivity lead to changes in the division of labour. When the

\footnotetext{
${ }^{2}$ Originally Smith (1776) related the division of labour to the extent of the market. Now, more than two centuries later, markets have become very large, we know that many people within one market perform the same tasks without further specialisation. Smith already noticed that communication costs are crucial in determining the division of labour: "Were there no other communication between those two places, therefore, but by land-carriage, as no goods could be transported from the one to the other, except such whose price was very considerable in proportion to their weight, they could carry on but a small part of that commerce which at present subsists between them, and consequently could give but a small part of that encouragement which they at present mutually afford to each other's industry." In Smith, time reduction in communication costs as a result of the introduction of "communication by water-carriage" increased the incentives for specialisation. Obviously, production costs have since then decreased so much compared to communication costs that now a decline in much more subtle communication between workers in the same workplace, already makes a difference.
} 
gains from computer adoption are due to a fall in communication costs between workers, there will be more specialisation. The observed trends in organisational structures seem to be more in line with the case where computer technology increases productivity in separate tasks, so the benefits of specialisation and the division of labour have diminished.

When gains in productivity are not equal for different tasks or for different groups of workers, computer adoption and the related adjustments in the division of labour will lead to shifts in the demand for labour. Our approach allows for several explanations why labour demand has shifted in favour of skilled workers. The most straightforward explanation follows from assuming that communication is a routine tasks, i.e. skilled workers have a larger advantage in production than in communication. Consequently, unskilled workers spend a larger fraction of their time on production, and experience a larger fall in demand when productivity in production tasks increases. These effects explain a tendency towards generalisation of jobs, with an increase in the demand for skilled labour. An implication of this interpretation is that the relative increase in communication time reduces the productivity differential between skilled and unskilled labour, therefore counterbalancing the tendency toward increased demand for skilled labour.

Based on a panel of Dutch establishments we present suggestive evidence consistent with this approach. In the 1990s computer adoption is generally associated with a change towards a more generic organisational structure. This is revealed by less diversity in the types of workers employed, a smaller fraction of indirect workers, and a lower standard deviation of wages. Since the vast majority of firms have a product oriented organisational structure, also the decrease of team size reflects a more generic structure. A rise in the number of hierarchical layers suggests that these firms substitute the increased workload related to communication with a more hierarchical structure. When we separate establishments - based on the pattern of computer adoption - between those that are more likely to benefit from production gains and those that have gained more from improved communication, we observe that there is a tendency towards generalisation in the first group, while in the latter group specialisation is more important. While most establishments seem to belong to the first groups, establishments in the second group who benefit relatively more from gains in communication - are typically part of larger organisations, export part of their production, use more advanced technologies, face a 
higher degree of competition, and compete in the high-quality segment.

These results are partly in contrast with the interpretations concerning organisational changes in the literature that focusses on workplace innovation. Both approaches are able to explain the link between computerisation and changes in the division of labour, but the innovations literature argues that computerising firms can further improve their productivity by emphasising team work and cooperation, while our approach suggests that computerisation decreases time needed for production tasks and increases communication time. The organisational changes that result are an attempt of the firm to reduce this increasing load of communication time. Both approaches predict an increase in time devoted to communication per employee, but our approach predicts a reduction in communication time when measured in units of output. While theories based on workplace innovations would predict a delayering of the organisational structure, the positive relationship between the introduction of computer equipment and hierarchical layers we find in this paper is consistent with an increase in the workload related to communication.

Both approaches can also be regarded as complements. When the optimal organisational structure changes - either in one or the other direction - workers will have to cope with this change, leading to disadvantages for less adaptable workers. Research by Aubert et al. provides ample evidence that indeed older workers are affected by organisational change, mainly through a lower probability of being hired. ${ }^{3}$

The approach developed in this paper is related to a number of previous studies on the division of labour in markets and firms that do not consider technological change. Baumgardner (1988) derives that when the division of labour is limited by market size each worker specialises in different activities, which may well describe the position of specialists in rural markets. ${ }^{4}$ Similar to our model, Becker and Murphy (1992) emphasise that the gains of specialisation are more likely to be limited by coordination cost and the level of knowledge in a market than by market size. Bolton and Dewatripont (1994) show that in the presence of returns to specialisation it may be efficient to have different workers share the same job despite the increased time cost of communication. ${ }^{5}$ Work

\footnotetext{
${ }^{3}$ See also Borghans and ter Weel (2002a), Friedberg (2002) and Weinberg (2005) for the effects of computerisation on the demand for older workers.

${ }^{4}$ Similarly, Rosen (1983) uses the concept of human capital specific to particular activities to generate gains from specialisation. Non-specialisation occurs when the costs of investment in different skills are nonseparable.

${ }^{5}$ However, a crucial assumption of their model is that the firm's organisation of labour is fixed and cannot be changed at reasonable costs to achieve a more efficient assignment of workers to jobs. As a result of this assumption, some of the firm's workers may be idle for some time. Other related work is done by Radner (1993) whose model is concerned with
} 
on organisational and technological change that is related to this paper is carried out by Milgrom and Roberts (1990) and Lindbeck and Snower (2000); the former focus on changes in production technology and the latter emphasise changes in the nature of work. Like Aghion et al. (1999) we argue that technological change is the driving force of the changing division of labour and that changes in organisational design are of a secondary nature. Bresnahan (1999) argues that computer-intensive production is likely to be more skill-intensive when complementary changes to organisational practices are made. Finally, Borghans and ter Weel (2004) explore mechanisms through which the optimal organisational structure changes as a result of technological change. From a theoretical perspective this model are also related to Rosen (1978), who shows that production functions can be described as the outcome of the optimal assignment of workers over heterogeneous tasks. This offers the possibility to analyse changes in the production process explicitly. ${ }^{6}$

Empirically our study is related to the work of Black and Lynch (2001; 2004), Brynjolfsson and Hitt (2003) and Bertschek and Kaiser (2004), who find that investments in computer technologies have enhanced firm productivity and have led to skill upgrading without focussing on the task assignment of workers in firms. The findings of Osterman (1994), Caroli and Van Reenen (2001) and Bresnahan et al. (2002) suggest both independent and complementary effects of organisational change and computer technology adoption on the demand for labour in Britain, France and the United States. However, these studies focus on decentralisation of authority within firms, whereas the present paper addresses the effects of technological change on the division of labour and the task assignment of workers in establishments. The changes in the assignment of workers to tasks as a result of technological change is related to papers by Borghans and ter Weel (2002b), Autor et al. (2003) and Spitz (2003), but they focus on individual workers and do not take into account worker organisation in establishments as we do here.

The paper is organised as follows. In Section 2 we present the model. Then we discuss the data. Section 4 presents the estimation results. Section 5 concludes.

\footnotetext{
minimising delay in processing tasks through job rotation to reduce the time workers stand idle.

${ }^{6}$ This feature of the model is also related to Sah and Stiglitz (1985), Sobel (1992) and Kremer (1993) who focus on the effects of failure on a product's value and try to model the ways to isolate the impact of mistakes and lessen the effects of detrimental shocks. Kremer (1993) derives that it is most efficient to match higher skilled workers with other higher skilled workers. Sah and Stiglitz (1985) and Sobel (1992) apply a similar theory to reliability in organisations by focussing on the subdivision of tasks. Sah and Stiglitz compare organisations where a number of workers have to approve a project to ones where a single worker has to approve a project. Sobel derives the optimal scale of operation by deriving the size of the task that has the minimum expected costs per step.
} 


\section{Model}

\subsection{Basic setting}

We assume an economy characterised by a competitive labour market and assume that firms are sufficiently small to prevent them from exerting market power. To produce one unit of output, a continuum of tasks $x \in[0,1]$ with density $f(x)$ and cumulative density $F(x)$ has to be performed. A firm potentially employs $n$ types of workers indexed $1, \ldots, n$. Demand for type $i \in\{1, \ldots, n\}$ is denoted by $L_{i}$. The time a worker of type $i$ needs to perform his tasks is described by the function $\tau_{i}(x, \gamma)$, where $\gamma$ is a productivity parameter which allows us to analyse what happens when productivity is increased as a result of computer adoption. Without computer technology $\gamma=1$, but after computer adoption and with computers becoming more powerful over time $\gamma<1$. Worker $i$ 's wages equal $w_{i}{ }^{7}$

Tasks are sorted on the interval $[0,1]$ such that $\tau_{i}(x, \gamma) / \tau_{i+1}(x, \gamma)$ increases with $x$, i.e. worker $i$ 's comparative advantage (compared to worker $i+1$ ) decreases with $x$, and lower values of $i$ will be associated with lower skilled workers. When tasks are divided between different types of workers, cost minimisation yields a point $\mu_{i}\left(\right.$ with $\mu_{0}=0$ and $\left.\mu_{n}=1\right)$ such that $i$ performs all tasks on the interval $\left[\mu_{i-1}, \mu_{i}\right]$. The parameters $\mu_{i}$ describe the division of labour in the firm. If $\mu_{i-1}=0$ and $\mu_{i}=1$ the production process is completely generic and workers of type $i$ perform all the work. In contrast, if there is equal demand for a large variety of worker types many workers carry out specific tasks and a high degree of specialisation is reached.

Figure 1 provides a graphical example of the model we have in mind. The figure gives an example of a firm with five types of workers. The parameter values used are shown below the figure. The upper panel shows the wage costs (i.e., the time requirements multiplied by the wage) of each of these five workers for the tasks on the interval $[0,1]$. From cost minimisation it follows that workers are assigned to tasks in which their comparative advantage is exploited and the division of labour will be optimal. In this example workers of type 1 perform the tasks on the interval $\left[\mu_{0}, \mu_{1}\right]$, workers of type 2 the tasks on the

\footnotetext{
${ }^{7}$ More generally, the time needed for worker $i$ with skill level $S_{i}$ to perform the tasks could be described by $\tau_{i}(x, \gamma, S)$. Based on a wage function $w\left(S_{i}\right)$, the optimal division of labour and the optimal skill requirements per group have to be analysed simultaneously. When a large number of worker types is distinguished - with potentially 0 employment - the same results can be obtained in a model that only investigates the division of labour.
} 
interval $\left[\mu_{1}, \mu_{2}\right]$ and so on. The shaded areas show the wage-bill shares of each of the five types of workers.

Unless the production process is completely generic, and apart from the time workers need to perform their own set of tasks, there is also time required for the coordination of work to manufacture one unit of output. We focus on the communication between workers that carry out different tasks for the production of the same good and do not take into account communication to coordinate the work of workers who carry out similar tasks. ${ }^{8}$ Assuming that each couple of tasks - or at least all tasks that are within close distance to the tasks of a certain worker - requires an equal amount of coordination time $(\delta)$ for both workers involved, coordination time between workers $i$ and $j$ is equal to $\delta\left(F\left(\mu_{i}\right)-F\left(\mu_{i-1}\right)\right)\left(F\left(\mu_{j}\right)-F\left(\mu_{j-1}\right)\right)$. Total communication time for worker $i$ equals $\delta\left(F\left(\mu_{i}\right)-F\left(\mu_{i-1}\right)\right)\left(\Omega-F\left(\mu_{i}\right)-F\left(\mu_{i-1}\right)\right)$, in which $\Omega$ denotes the number of tasks worker $i$ has to communicate about. In the basic case, $\Omega=\int_{0}^{1} f(x) d x$ but it is unlikely that every worker has to communicate about his work with every other worker in the firm. Hence, $\Omega$ can be smaller but we need that every worker at least has to communicate about the tasks within close vicinity of his own tasks. Of course, this is a rather crude assumption and communication requirements for each combination of tasks could be different; communication about a larger range of tasks could be more efficient than communication about each task separately. An alternative model is to define the time needed by worker $i$ to communicate about his tasks with others as a function $c\left(\delta\left(F\left(\mu_{i}\right)-F\left(\mu_{i-1}\right)\right)\right)$, with $c^{\prime}>0$ and $c^{\prime \prime}<0$. Similarly, rather than meeting each colleague separately, a worker could inform his manager, who could inform all the colleagues. This yields hierarchical structures as developed by Radner (1993). In our model such a structure yields returns to scale when many workers have to be informed, and this could be modelled as $h\left(\delta\left(\Omega-F\left(\mu_{i}\right)-F\left(\mu_{i-1}\right)\right)\right)$, with $h^{\prime}>0$ and $h^{\prime \prime}<0$. Hierarchical levels in this view could be substitutes for increased communication. These extensions do not alter the findings of our model qualitatively, and to keep notation simple we follow the straightforward approach without introducing hierarchical layers.

\footnotetext{
${ }^{8}$ When this kind of communication between workers sharing the same tasks would be included, assuming that every worker participates a given amount of time in communication about each task, a more generic organisation would increase these coordination costs because more workers are involved in meetings about a certain task. It is more realistic to regard this kind of coordination to be endogenous. When more workers share the same function, the probability that one of them has an insight that is beneficial for the others increases, so the organisation will gain. Ichniowski et al. (2003) point at the externalities that are associated with knowledge sharing and argue that in more generic organisations the marginal value of new work practices that promote cooperation will be higher.
} 
The bottom panel of Figure 1 shows the coordination between workers needed to produce output, which is reflected in terms of communication time. The lines show that the more tasks a worker is performing the less the time needed to communicate. The shaded areas are the tasks communication is required about and it is easy to see that these areas will become smaller the less communication is performed between workers. If communication is costly this reveals a trade-off between specialisation and communication. This trade-off will be explored in more detail in the remainder of this section.

Given total output $(Y)$, the demand for each worker type $i \in\{1, \ldots, n\}$ equals

$$
L_{i}=Y(\underbrace{\int_{\mu_{i-1}}^{\mu_{i}} \tau_{i}(x, \gamma) f(x) \mathrm{d} x}_{T_{i}^{p}}+\underbrace{\delta\left(F\left(\mu_{i}\right)-F\left(\mu_{i-1}\right)\right)\left(\Omega-F\left(\mu_{i}\right)-F\left(\mu_{i-1}\right)\right)}_{T_{i}^{c}}) .
$$

Total demand for labour equals $L=\sum_{i=1}^{i=n} L_{i}=Y\left(T^{p}+T^{c}\right)$. A concentration index $\sum_{i=1}^{i=n}\left(L_{i} / L\right)^{2}$ is well able serve as an indicator of the division of labour within firms. We explore such an indicator of concentration in the empirical analysis below to distinguish between differences in the division of labour across firms.

The costs, $C$, to produce one unit of output equal

$$
\begin{aligned}
C & =\sum_{i} w_{i}\left(\int_{\mu_{i-1}}^{\mu_{i}} \tau_{i}(x, \gamma) f(x) \mathrm{d} x+\int_{\mu_{i-1}}^{\mu_{i}} \delta f(x)\left(\Omega-\int_{\mu_{i-1}}^{\mu_{i}} f(x) \mathrm{d} x\right) \mathrm{d} x\right) \\
& =\sum_{i} w_{i}\left(T_{i}^{p}+T_{i}^{c}\right)
\end{aligned}
$$

which consist of the wage costs and time requirements of the workers and the communication costs required for the production process. Note, it follows from equation (2) that there is a clear trade-off between communication and specialisation: if the firm increases the number of tasks to be performed by worker $i$, it saves on expensive communication time. This can also be seen in the bottom panel of Figure 1. If the number of tasks is divided between less workers the number of tasks that requires communication is reduced (i.e., the surface of the gray areas become smaller).

To focus on the division of labour, we start to analyse the model assuming that the productivity gain in each task is proportional for all $i: \tau_{i}(x, \gamma)=\gamma \tau_{i}(x)$ for all workers. In the general specification we allow the effect of $\gamma$ on $\tau$ to differ for different combinations of $i, x$. Such a more general specification leads to biases in the demand for specific skill groups. We assume that $\delta$ is equal for all workers and tasks. As such this might be a 
plausible assumption, but below we will discuss the case in which $\delta_{i}(x, \gamma)$ is a function of $i$ and $x$ with a pattern changing in $\gamma$ as well.

Minimising costs with respect to the division of labour yields the following condition:

$$
\begin{aligned}
\frac{\partial C}{\partial \mu_{i}}= & w_{i} \tau_{i}\left(\mu_{i}\right) f\left(\mu_{i}\right)-w_{i+1} \tau_{i+1}\left(\mu_{i}\right) f\left(\mu_{i}\right) \\
& +w_{i} \delta f\left(\mu_{i}\right)\left(\Omega-2\left(F\left(\mu_{i}\right)-F\left(\mu_{i-1}\right)\right)\right) \\
& +w_{i+1} \delta f\left(\mu_{i}\right)\left(2\left(F\left(\mu_{i+1}\right)-F\left(\mu_{i}\right)\right)-\Omega\right)=0 .
\end{aligned}
$$

This result implies that if $\delta=0$ the worker who is able to perform the task at the lowest costs will carry out the task, i.e. $\frac{\partial C}{\partial \mu_{i}}=w_{i} \tau_{i}\left(\mu_{i}\right) f\left(\mu_{i}\right)-w_{i+1} \tau_{i+1}\left(\mu_{i}\right) f\left(\mu_{i}\right)=0$. If there is a need for coordinating tasks $\delta>0$. In this case equation (3) suggests that the worker with the largest number of tasks will get additional tasks, because this saves expensive communication time. An implication of this result is that the firm accepts that workers who are at the margin less able in performing a certain task will nevertheless carry out this task, because communication time will be economised on. ${ }^{9}$

Given the first order condition in equation (3), the second order condition equals

$$
\frac{\partial^{2} C}{\partial \mu_{i}^{2}}=f\left(\mu_{i}\right)\left(w_{i} \tau_{i}^{\prime}\left(\mu_{i}\right)-w_{i+1} \tau_{i+1}^{\prime}\left(\mu_{i}\right)-2 \delta f\left(\mu_{i}\right)\left(w_{i-1}+w_{i}\right)\right)>0 .
$$

This model yields a trade-off between specialisation and communication because there exists a trade-off between production time $\left(\tau_{i}(x)\right.$ and $\left.\tau_{i+1}(x)\right)$ and communication costs $(\delta)$. The more specialised workers are, the more communication is necessary to coordinate all workers' activities and the larger is the variety of different workers the firm employs for a given firm size (e.g., Baumgardner, 1988, Becker and Murphy, 1992 and Bolton and Dewatripont, 1994). In addition, this model of time requirements implicitly describes a production function. By choosing the optimal division of tasks, a relationship between the inputs (time used by the workers) and output is obtained. Rosen (1978) discusses this approach to denote production functions, provides some examples and argues that it yields an interesting opportunity to explicitly model particular features of the production process. Our focus in the remainder of this paper is on the effects of computer technology on the production process and the optimal division of labour between the workers.

\footnotetext{
${ }^{9}$ Equation (3) also depends on the wages of the workers, reflecting that one reason for employers to change the division of labour is a change in relative wages. When the wages of worker $i+1$ increase in comparison with the wages for worker $i$, employers will shift some tasks from $i+1$ to $i$ to diminish the cost increases. The resulting division of labour will be such that the tasks of worker $i+1$ will be concentrated more on the performance of tasks in which he has a clear comparative advantage. For that reason, an increase in wage differentials between skilled and unskilled workers leads to changes in the division of labour and an increase in the job complexity of both skilled and unskilled workers.
} 


\subsection{Computer technology adoption}

When a firm considers the reasons to adopt computer technology, it could expect computer technology to (i) reduce the time needed for the coordination (or to reduce communication costs) of activities between workers or (ii) to reduce the time needed to perform specific tasks.

We assume that workers do not share computers and that the costs of using a computer are equal for all workers, so the break-even point for cost-efficient computer adoption can be calculated. When computer technology has only a productivity advantage the benefits

are equal to $(1-\gamma) w_{i}\left(\frac{T_{i}^{p}}{T_{i}^{p}+T_{i}^{c}}\right)$, which suggests that the advantage of computer adoption is higher the higher the worker's wage and the fewer time is used for communication with co-workers. Note that the adoption decision for one type of worker in this case does not depend on the adoption of others.

When the gains from using computer technology stem from lower communication costs, the decisions to adopt computer technology become interrelated. If a projection of the diffusion of computer technology within a firm ranges from the most skilled and most expensive workers to the workers with the lowest wages, it can be shown that the benefits from computer use will decrease due to lower wages but at the same time also increase for two reasons: (i) the larger the fraction of workers in a firm already using computer technology, the larger will be the benefit of an additional user; and (ii) when more workers use computer technology the benefits for those who already adopted will increase further. Consequently, the benefits from computer use might increase more with every additional computer user than the total costs. When computer technology is merely adopted for communication reasons, it can be expected that all workers adopt computer technology at the same point in time. In more general terms, computer technology adoption tends to be concentrated at one point in time if communication benefits are the main determinant of adoption, while the diffusion pattern is smoother over time when productivity benefits are relatively more important. This theoretical prediction will be at the core of the empirical analysis to distinguish firms that adopt computers for communication reasons from firms that use computer technology to produce more efficiently. 


\subsubsection{Communication costs}

First, we more formally investigate what would be the effect of a reduction of communication costs $(\delta)$ on the optimal division of labour between workers. Defining $\mu_{i}$ in equation (1) as an implicit function of $\delta$ (i.e., $\mu_{i}(\delta)$ ), comparative statics can be obtained by taking the derivative of equation (2) with respect to $\delta$. When taking only the effect on $\mu_{i}$ into account and thus keeping $\frac{\mathrm{d}_{\mu_{i-1}}}{\mathrm{~d} \delta}=0$ and $\frac{\mathrm{d} \mu_{i+1}}{\mathrm{~d} \delta}=0$ we obtain

$$
\begin{gathered}
w_{i} \tau_{i}^{\prime}\left(\mu_{i}\right) \mu_{i}^{\prime}-w_{i+1} \tau_{i+1}^{\prime}\left(\mu_{i}\right) \mu_{i}^{\prime}-2 \delta\left(w_{i}+w_{i+1}\right) f\left(\mu_{i}\right) \mu_{i}^{\prime}+ \\
w_{i}\left(\Omega-2\left(F\left(\mu_{i}\right)-F\left(\mu_{i-1}\right)\right)\right)+w_{i+1}\left(2\left(F\left(\mu_{i+1}\right)-F\left(\mu_{i}\right)\right)-\Omega\right)=0,
\end{gathered}
$$

which yields

$$
\frac{\mathrm{d} \mu_{i}}{\mathrm{~d} \delta}=\frac{\left(w_{i+1}-w_{i}\right) \Omega+w_{i} 2\left(F\left(\mu_{i}\right)-F\left(\mu_{i-1}\right)\right)-w_{i+1} 2\left(F\left(\mu_{i+1}\right)-F\left(\mu_{i}\right)\right)}{\frac{\partial^{2} C}{\partial \mu_{i}{ }^{2}}} .
$$

The first term of equation (6) shows that decreasing the costs of communication will lower $\mu_{i}$ and thus shift tasks to the worker with a higher wage. The reason for this is that communication time for a certain task is assumed to be equal for every worker regardless of his skill level and wages, while productivity increases with the skill level. Consequently, skill differences between two types of workers become larger when communication becomes less important. We will further explore this skill bias in Section 2.3 below.

The second and the third part of the equation are, for the moment, the more interesting parts of the effect of reduced communication costs. When communication costs go down tasks will be shifted from workers with the largest set of tasks to workers with the smallest set of tasks, i.e. a higher degree of specialisation will be optimal. As a result of lower costs of communication due to computer technology adoption, firms will reorganise by increasing the level of specialisation and stressing the division of labour. ${ }^{10}$

\subsubsection{Production costs}

Secondly, computer technology might also reduce the time needed to carry out each task, i.e. $\gamma$ might decrease. Evaluating the effect for $\gamma=1$ and defining $\mu_{i}$ as a function of $\gamma$ gives

$$
\mu_{i}^{\prime}=\frac{w_{i} \tau_{i}\left(\mu_{i}\right)-w_{i+1} \tau_{i+1}\left(\mu_{i}\right)}{\frac{\partial^{2} C}{\partial \mu_{i}^{2}}} .
$$

\footnotetext{
${ }^{10}$ This result is consistent with the results obtained by Becker and Murphy (1992) and Bolton and Dewatripont (1994). They study the trade-off between communication costs and specialisation and find that lower communication costs increase the amount of specialisation in the economy.
} 
Based on the first order condition (3) and making use of equation (4) this can be rewritten as

$$
\frac{\mathrm{d} \mu_{i}}{\mathrm{~d} \gamma}=\delta \frac{\left(w_{i}-w_{i+1}\right) \Omega-w_{i} 2\left(F\left(\mu_{i}\right)-F\left(\mu_{i-1}\right)\right)+w_{i+1} 2\left(F\left(\mu_{i+1}\right)-F\left(\mu_{i}\right)\right)}{\frac{\partial^{2} C}{\partial \mu_{i}{ }^{2}}} .
$$

Apart from the scalar $\delta$ this effect of computerisation on the division of labour is exactly the opposite of the effect of lower communication costs. This yields that in contrast to the decreasing costs of communication, reduced production time resulting from computer adoption leads to a more generic division of labour in the sense that the number of tasks carried out by the worker with the largest set of tasks is increasing.

\subsubsection{Which effect dominates?}

In the model, the question whether computerisation leads to specialisation or more generic functions boils down to the question whether in absolute terms production time or communication time is affected stronger. When thinking of $\gamma$ as a parameter affecting both production time $\tau$ and the time needed to communicate $\delta(\gamma)$ the total effect of $\gamma$ on the division of labour equals:

$$
\begin{aligned}
\frac{\mathrm{d} \mu_{i}}{\mathrm{~d} \delta} & =\frac{\mathrm{d} \mu_{i}}{\mathrm{~d} \delta} \frac{\mathrm{d} \delta}{\mathrm{d} \gamma}+\frac{\mathrm{d} \mu_{i}}{\mathrm{~d} \gamma} \\
& =\left(\frac{\mathrm{d} \delta}{\mathrm{d} \gamma}-\delta\right) \frac{\left(w_{i+1}-w_{i}\right) \Omega+w_{i} 2\left(F\left(\mu_{i}\right)-F\left(\mu_{i-1}\right)\right)-w_{i+1} 2\left(F\left(\mu_{i+1}\right)-F\left(\mu_{i}\right)\right)}{\partial^{2} C / \partial \mu_{i}{ }^{2}}
\end{aligned}
$$

implying that there will be net specialisation when

$$
\frac{\frac{\mathrm{d} \delta}{\mathrm{d} \gamma}}{\delta}>1
$$

From the comparative statics results two main conclusions can be drawn with respect to the relationship between computer technology adoption and the division of labour. First, both changes in communication costs and changes in production time induce changes in the division of labour. This result holds despite the fact that reduced production time leaves all features of the communication structure unaffected. Secondly, both changes will affect the division of labour in a different way. Lower communication costs will promote a greater division of labour and result in a more specialist form of workplace organisation, whereas lower production time will induce a more generic organisational structure in which one worker performs relatively many tasks. 


\subsubsection{Simulation results}

To provide visual insight into the role of communication costs in determining the division of labour we have simulated the case in which communication costs gradually rise. Figure 2 provides the results of this simulation exercise. The horizontal axis measures relative communication $\operatorname{costs} \delta / \gamma$. On the vertical axis the continuum of tasks $x \in[0,1]$ is plotted. The picture is based on simulations for a case with five types of workers with hierarchical skill levels from 1 to 5 and a total number of 250 tasks, in which we gradually increase communication costs. Consistent with the patterns depicted in Figure 1, we assume that the time needed for a worker of type $i$ to perform task $x$ equals $\tau_{i}(x, 1)=e^{a_{i} x}$. The productivity parameters $a_{i}$ have been set equal to $4,3,1.5, .75$ and .32 for the various skill groups. Relative market wages of these skill groups equal $w_{2}=1.25 w_{1}, w_{3}=2.20 w_{1}$, $w_{4}=3.55 w_{1}, w_{5}=5.00 w_{1}$. Initially, when communication costs are zero, the firm's division of labour is fully determined by the product of wages and time needed to perform a task, for each task separately.

When communication costs increase the firm shifts tasks from workers with a smaller set of tasks to workers with a larger set of tasks to save on expensive communication time. This process of generalisation depends on the skill level and wages of the workers involved. The simulation results show that first the worker in between the highest and middle skilled and the one in between the lowest and middle skilled worker disappear. The interpretation of this result is that the firm assigns tasks to workers who are less suitable to carry out certain tasks to the tasks previously performed by the workers with skill level 2 and 4 to save on expensive communication. This will occur when the cost of communication will outweigh the lower productivity in these tasks. When communication costs rise further only the middle-skilled (skill level 3) worker remains employed and carries out all job activities. This is a situation of a totally generic organisational structure.

\section{$2.3 \quad$ Skill upgrading}

The adoption of computer technology leads to a bias in labour demand and changes in the division of labour when the decrease in time needed to perform tasks is not proportional for all tasks or workers. To see this, define for a certain division of labour $\hat{\tau}_{i}^{c}(x)=$ $\tau_{i}(x, \gamma)+\delta^{c}\left(\Omega-F\left(\mu_{i}\right)+F\left(\mu_{i-1}\right)\right)$ and $\hat{\tau}_{i}^{n c}(x)=\tau_{i}(x, 1)+\delta^{n c}\left(\Omega-F\left(\mu_{i}\right)+F\left(\mu_{i-1}\right)\right)$ as 
the total production time needed by agent $i$ to perform task $x$ with $(c)$ and without $(n c)$ computer technology, respectively. Now, two sources of non-neutral changes have to be distinguished.

First, the ratio $\frac{\hat{\tau}_{i}^{c}(x)}{\hat{\tau}_{i}^{c c}(x)}$ can be non-constant in $x$, implying that the time needed for the performance of some tasks falls stronger as a result of computerisation than the time requirements for other activities. Secondly, for the performance of the same task the ratio $\frac{\hat{\tau}_{i}^{c}(x)}{\hat{\tau}_{i}^{n c}(x)}$ can differ between different types of workers. In the latter case the productivity of higher skilled workers increases more in this specific task. The reason for this type of bias could be that the productivity gain is related to the skills of the worker directly, or it could be related to the fact that a task consists of two subtasks. If the time needed for one subtask is more strongly related to the skill level than the time needed to carry out the other subtask (e.g., a task consists of a non-routine and a routine subtask), and if computerisation proportionally decreases the non-routine part more, higher skilled workers gain relatively more in terms of time reductions.

This non-neutral decrease in the time needed to perform certain tasks has two opposite consequences. First, when the division of labour is left unchanged, and since $L_{i}=Y\left(T_{p}+T_{c}\right)$, less time is required to produce the same level of output. A bias in the time gain from computer technology adoption therefore disproportionally lowers labour demand for those workers who benefit most from increased productivity. Increased productivity, on the other hand, leads to increased demand on the product market and acts as a counterbalancing factor on labour demand. The increase in the demand for the firm's products increases demand for all types of workers in the production process, so in relative terms those workers who face the largest increase in productivity loose demand when no changes in the division of labour are taken into account.

Secondly, our model can be used to show the effects of a skill bias on the division of labour because the productivity gain from using computer technology $\gamma$ is a function of $i$ and $x: \tau_{i}(x, \gamma)$ with $\frac{\partial \tau_{i}(x, \gamma)}{\partial \gamma}>0$. Equation $(7)$ can now be extended to

$$
\frac{\partial \mu_{i}}{\partial \gamma}=\delta \frac{w_{i} \tau_{i}\left(\mu_{i}\right) \frac{\partial \tau_{i}}{\partial \gamma}-w_{i+1} \tau_{i+1}\left(\mu_{i}\right) \frac{\partial \tau_{i+1}}{\partial \gamma}}{\frac{\partial^{2} C}{\partial \mu_{i}^{2}}}
$$


which is equal to $(7)$ when $\frac{\partial \tau}{\partial \gamma}=1$. This expression can be rewritten as

$$
\begin{gathered}
\frac{\partial \mu_{i}}{\partial \gamma}=\delta \frac{\left(\left(w_{i}-w_{i+1}\right) \Omega-w_{i} 2\left(F\left(\mu_{i}\right)-F\left(\mu_{i-1}\right)\right)+w_{i+1} 2\left(F\left(\mu_{i+1}\right)-F\left(\mu_{i}\right)\right)\right) \frac{\partial \tau_{i}}{\partial \gamma}}{\frac{\partial^{2} C}{\partial \mu_{i}{ }^{2}}}+ \\
\frac{w_{i} \tau_{i}\left(\mu_{i}\right)\left(\frac{\partial \tau_{i}\left(\mu_{i}, \gamma\right)}{\partial \gamma}-\frac{\partial \tau_{i+1}\left(\mu_{i}, \gamma\right)}{\partial \gamma}\right)}{\frac{\partial^{2} C}{\partial \mu_{i}{ }^{2}}} .
\end{gathered}
$$

The second term of this equation reflects the additional changes in the division of labour related to the skill bias in labour demand. Note that when the advantage of the new technology differs between tasks, this has no direct effect on the division of labour. Consequently, only the demand for labour performing this task is affected. When two types of workers have proportionally different gains from computer use, the optimal division of labour will be affected. Comparison of worker $i$ to worker $i+1$ yields that $\mu_{i}$ will decrease - and thus the more skilled worker $i$ will get more tasks - when $\frac{\partial \tau_{i}}{\partial \gamma}<\frac{\partial \tau_{i+1}}{\partial \gamma}$. In a skill interpretation this is the case when skills complement computer technology; in the routine vs. non-routine task interpretation, this result implies that subtasks, relatively independent of skill, gain more from computerisation than the non-routine subtasks.

In the previous section it has been shown that a decrease in time needed for communication could lead to a shift of tasks towards more skilled workers. This is actually a good example of the routine vs. non-routine interpretation. When communication time is independent of skills, while productivity depends on the skill level of the worker, a decrease in communication time is in fact a decrease in the routine aspect of a job, and therefore leads to a skill bias in labour demand. Consequently, it is not because skilled workers are better communicators, but because they are equally good communicators compared to unskilled workers, which leads to an increased demand for skilled workers from improved communication technology.

\section{Empirical Implementation}

To empirically assess changes in the organisation of work as a result of computer technology adoption we define a number of firm characteristics that capture the division of labour and the skill level of the workforce. Furthermore, we define an empirical strategy, based on the pattern of computer technology adoption of establishments, to capture the distinction between firms adopting computer technology for communication advantages 
and those that adopt the new technology for productivity reasons. Finally, we also explore the consequences of computer technology adoption for the demand for different types of labour.

\subsection{Data}

The data we use come from a survey among Dutch establishments carried out on a biannual basis by the Institute for Labour Studies (OSA) in the period 1990-1996. ${ }^{11}$ Many establishments are in the survey for several years, so we can use the data to construct a panel of establishments over this period of time. The primary advantage of the database is that it allows us to exploit a nationally representative survey of establishments to estimate the effects of the adoption of computer technology on the division of labour. Another advantage is that we have observations on establishments at different points in time in a crucial and turbulent period regarding the boom in information and communication technology adoption to control for unobserved time invariant firm characteristics. Although the length of time is generally relatively short to investigate developments over time, we believe that the 1990s are sufficiently characterised by major changes in the use of computer technology to capture a significant number of changes in the division of labour. The period is also sufficiently limited to warrant that the results are not driven or influenced by attrition or the entrance of a great many new firms. ${ }^{12}$

Since changing the division of labour within an establishment is only possible when this has a sufficient scale, we only include establishments with more than 10 employees in the database subject to empirical analysis. ${ }^{13}$ The change in computer technology use is measured by the change in the number of personal computers per employee. While this measure is incomplete and misses workers who use devices with embedded microprocessors, it does reflect a particularly prevalent form of computer technology that has been important in both the production process and in facilitating modern forms of communication within most firms in this period. ${ }^{14}$ In the data we have information about

\footnotetext{
${ }^{11}$ Borghans and ter Weel (2003) provide a detailed outlay of the data and discuss and compare the data with other data sources.

${ }^{12}$ The results presented in Osterman (2000) suggest that especially the period 1985-1995 is characterized by a large number of organisational changes that are most likely correlated with the adoption of computer technologies. Previous studies on workplace reorganisation as a result of recent technological changes (e.g., Black and Lynch (2001), Caroli and Van Reenen (2001) and Bresnahan et al. (2002)) use comparable time frames.

${ }^{13}$ Most of the establishments that do not meet this criterium actually have only one worker or a very low number of workers, which renders an analysis of the division of labour obsolete.

${ }^{14}$ See e.g., Bresnahan and Greenstein (1996), Bresnahan (1999) for a discussion and overview of the different uses of
} 
computer technology adoption in the establishments in 1990, 1992, 1994, and 1996. This allows us to investigate changes in three two-year periods. Based on pooled data from these two-year periods, Table 1 presents the mean and standard deviation of the biannual change in computer technology use, which equals 5.1 percent with a sizeable standard deviation of .223 suggesting the differences in the rates of computer technology adoption between establishments to be relatively large.

We relate changes in computer use to measures regarding the division of labour and the skill level of the workforce. Direct information or measures of the division of labour is very rare, but our source includes detailed establishment-level data, which relate to the division of labour. The data contain information about the employment structure, organisational structure and wages within establishments. With regard to changes in employment structure we use information about changes in the shares of skilled workers, which is measured as the share of workers with a higher degree of education such as higher vocational or university education. ${ }^{15}$ We also explore changes in the ratio of indirect to direct employees to assess changes in the relative importance of employing specialists. Finally, we construct a measure of concentration to address whether over time specialisation or generalisation of labour demand has become more influential: $\sum_{i=1}^{i=n}\left(L_{i} / L\right)^{2}$, based on a classification of educational attainment in five levels. This measure is related to the measure of total labour demand derived in Section 2.2 above. The second panel in Table 1 reports the means and standard deviations of these three measures of changes in employment structure. The numbers suggest that the degree of concentration has increased as well as the share of skilled workers. ${ }^{16}$ The former implies a tendency towards less specialisation, whereas the latter is consistent with the general trend towards upgrading experienced in most OECD countries since the 1980s. The change in the ratio of indirect to direct employees has generally fallen, which is in line with the trend towards less specialisation also observed from the change in the concentration index.

Another source of information about the division of labour can be found by investigating changes in the organisational structure of establishments. We do so by taking into account changes in average team size and the number of hierarchical layers within a firm.

\footnotetext{
computer technology over time and the distinct consequences this has for workplace organization.

${ }^{15}$ This level of education is comparable to a college degree in the United States and professional and university qualifications in the United Kingdom.

${ }^{16} \mathrm{On}$ average the change in the number of skilled workers has been 9.3 percent and the change in the employment of unskilled workers was -3.0 percent.
} 
Our data set also includes information about establishment size. Information from the earlier 1988 wave of the same survey reveals that about 78 percent of all establishments has a product or service oriented organisational structure. This implies that team size is a good reflection of the degree of specialisation in a firm. As mentioned in the previous section, the number of hierarchical layers reflects the extent to which the establishment tries to reduce communication costs. The third panel of Table 1 presents the mean values of these three variables. The numbers suggest that there exists a trend towards fewer hierarchical layers although the mean value is relatively small and the standard deviation is considerable. Average team size is increasing, which points towards a tendency towards more specialisation. However, comparable to the case of the number of layers, the number is also rather low and the standard deviation is sizeable. Finally, establishments have a tendency to become larger over time although only marginally so.

Our final measure to capture changes in the division of labour is to explore changes in the establishment's wage structure. We focus on the biannual changes in the log average wages paid by establishments and the change in the standard deviation of the log wages. The former suggests an increase in the average wages paid but the latter is more interesting revealing a large increase in the standard deviation of wages within establishments, which suggests that wage dispersion within establishments has increased considerably over a relatively short period of time.

\subsection{Empirical strategy}

The empirical strategy is to capture the effects of the adoption of computer technology on the division of labour within establishments. The model developed above has shown two distinct reasons for computer adoption on the division of labour: (i) establishments that benefit from computerisation mainly because of increased productivity in the performance of separate tasks and (ii) establishments that gain relatively more because of improved communication. Both reasons for computer adoption yield different predictions for the division of labour. When computer technology is mainly adopted for productivity reasons we expect the division of labour to become more generic, and when the technology is applied to improve coordination and communication between workers we expect a more specialised division of labour. 
To empirically discriminate between these two effects of computer adoption we use predicted differences in the adoption patterns of establishments. We assume that rapidly adopting establishments are more likely to use computer technology to improve coordination between workers and to save on expensive communication time, because coordination will only be effectively improved if a substantial fraction of the workforce adopts computer technology at the same time. When computer adoption occurs at a relatively slow or smooth pace we assume the technology to be more applied in terms of (individual workers') productivity gains.

Investigation of the pattern and pace of computer adoption over time within establishments is crucial for understanding changes in the division of labour, but it has been largely neglected by the empirical economic literature. A number of case studies have shown that large waves of computerisation automate routine job tasks within firms and make communication between workers more effective. This led to the creation of more specialised jobs or more narrowly defined jobs (e.g., Levy and Murnane (1996), Fernandez (2001), and Autor et al. (2002)). Complementary to this, Osterman's results suggest that such job designs are more likely to be implemented where management attaches importance to increasing customer service relationships (Osterman, 1994). From the computer technology's point of view, the increasing popularity of client-server computing in the 1990s has two potential effects on the adoption pace of computer technology. First, the clients (e.g., PCs) can be equipped with specialised software tailored towards the more effective performance of the individual worker's tasks. This would induce an adoption pattern such that specific (groups of) workers adopt computer technology, while others do not. This form of computer adoption induces a more generic division of labour with single workers carrying out more tasks as we have shown above. Second, client-server computing has the potential to make communication (e.g., via servers and email) between different workers and departments within an establishment more effective. When a critical mass of workers benefits from such a communication network, the firm will adopt such a system for its entire (or a large part of the) workforce at once with lower communication costs in mind. This form of computer adoption yields a division of labour that is more specialised, resulting in individual workers performing less production tasks and spending more time on communicating with others. 
As a starting point for the empirical analysis, we estimate the determinants of computer adoption to examine whether establishments who computerised the workplace rapidly are different from those who adopted computers at a more gradual pace. To do so, we first construct a measure to address the relative pace of computer adoption $\Gamma$ :

$$
\Gamma=\left(\frac{\Delta C_{90-92}}{\Delta C_{90-96}}\right)^{2}+\left(\frac{\Delta C_{92-94}}{\Delta C_{90-96}}\right)^{2}+\left(\frac{\Delta C_{94-96}}{\Delta C_{90-96}}\right)^{2},
$$

where $\Delta C$ is the change in computer technology use per employee in the relevant periods. The measure can be interpreted as the probability that two workers who started to use a computer between 1990 and 1996, adopted a computer in the same two-year sub-period. The maximum value of $\Gamma$ equals 1 and is observed when the change in computer technology use in one subperiod is equal to the overall change in computer technology use in the period 1990-1996. The minimum value of $\Gamma$ is equal to $\frac{1}{3}$, which is observed when the rate of computer technology adoption is equal in all three subperiods. In the data the mean value (standard deviation in brackets) of $\Gamma$ equals .723 (.192); the minimum value .339 and the maximum is 1 .

Applying a square term in defining $\Gamma$ is arbitrary to some extent, and we have considered the robustness of all our results carefully by using different powers in this index: the qualitative aspects of our regression results are not affected. Using higher order terms increases the slope of $\Gamma$ because the minimum value becomes lower whereas the maximum value remains one. ${ }^{17}$ Additionally, our measure using a square term is well-known as the Herfindahl index to measure the size of firms in relation to the industry and to serve as an indicator of the amount of competition among them. The main advantage of using our $\Gamma$ measure is that it gives a higher weight to more substantial changes in computer technology adoption, which we want to use to capture different reasons for adoption between establishments.

Figure 3 contains two panels presenting the patterns of computer adoptions by Dutch establishments in the period 1990-1996. Panel A presents the biannual changes in computer adoption rates in percentages for the three subperiods, which are equal to the denominators in equation (13). The figure shows a truncated plot of the changes in computer technology use over time. The numbers suggest that in most cases the changes are fairly small and that about 50 percent of the establishments in our sample is not adopt-

\footnotetext{
${ }^{17}$ For example, using a cubic term yields values of $\Gamma$ ranging from $\frac{1}{9}$ to 1.
} 
ing additional computer technology in each of the subperiods. ${ }^{18}$ This figure is consistent with the relatively low average rate of computer technology adoption reported in Table 1 above. Panel $B$ in Figure 3 shows a truncated plot of $\Gamma$ ranging from its theoretical minimum value of $\frac{1}{3}$ to its maximum value of 1 . It can be read from this figure that there are three peaks in the data. First, there is a substantial fraction of establishments around 0.50, which could indicate that the change in computer adoption is equal in two of the three subperiods and zero in the third subperiod. For example, if $\Delta C_{90-96}=0.30$ and $\Delta C_{90-92}=0.15, \Delta C_{92-94}=0$, and $\Delta C_{94-96}=0.15, \Gamma=\left(\frac{0.15}{0.30}\right)^{2}+\left(\frac{0.00}{0.30}\right)^{2}+\left(\frac{0.15}{0.30}\right)^{2}=0.50$. Of course other values for the denominator in which adoption occurs in all three years also work to obtain values for $\Gamma$ around $0.50 .{ }^{19} \mathrm{~A}$ second peak in the data is in the range around 0.75 . To obtain a value for $\Gamma$ close to $\frac{3}{4}$, computer technology adoption in one of the three subperiods has to be substantial. For example, if 85 percent of the total change in computer technology use is occurring in one subperiod and 15 percent in one of the two other subperiods $\Gamma=0.75$. When all subperiods are characterised by computer technology adoption, the change in computer use in one single subperiod has to be even higher than 85 percent. For example $\Gamma=\left(\frac{0.26}{0.30}\right)^{2}+\left(\frac{0.02}{0.30}\right)^{2}+\left(\frac{0.02}{0.30}\right)^{2}=0.76$. The final peak in Figure $3 \mathrm{~b}$ is around 1 . This value for $\Gamma$ implies that almost all changes in computer technology use within an establishment have taken place in one subperiod. For example, with 97 percent of the total adoption taking place in one subperiod and 1.5 percent in both other subperiods, $\Gamma=\left(\frac{0.005}{0.30}\right)^{2}+\left(\frac{0.29}{0.30}\right)^{2}+\left(\frac{0.005}{0.30}\right)^{2}=0.94$.

\section{Estimation Results}

\subsection{Determinants of Computer Adoption}

To obtain an impression what kind of establishments typically adopt computers in different fashions, we explain changes in $\Gamma$ by a number of establishment characteristics. The regression equation we consider for establishment $e$ is the following:

$$
\begin{aligned}
\Gamma_{e}= & C+\alpha_{1} O W N S_{e}+\alpha_{2} P R O D_{e}+\alpha_{3} E_{X P O_{e}}+\alpha_{4} M C O M P_{e}+ \\
& \alpha_{5} T C O M P_{e}+\alpha_{6} T E C H_{e}+\epsilon_{e},
\end{aligned}
$$

\footnotetext{
${ }^{18}$ These relatively low numbers might strike the reader as surprising. Taking into account our time frame of analysis, it should be noted that many firms already have adopted computer technologies by 1990 .

${ }^{19}$ For example $\Gamma=\left(\frac{0.185}{0.30}\right)^{2}+\left(\frac{0.10}{0.30}\right)^{2}+\left(\frac{0.015}{0.30}\right)^{2}=0.49$ and $\Gamma=\left(\frac{0.19}{0.30}\right)^{2}+\left(\frac{0.10}{0.30}\right)^{2}+\left(\frac{0.01}{0.30}\right)^{2}=0.51$.
} 
where $O W N S$ contains information about the ownership structure of the establishment, $P R O D$ captures the effects of producing different types of products, EXPO is a dummy for whether part of the production is exported and is used as an indicator to capture world wide competition, $M C O M P$ is a measure of the degree of market competition, TCOMP is an indicator of the type of competition faced by establishment $e$, and TECH measures the technology advancement of establishments in terms of performing its own R\&D or in terms of using advanced production technologies. $C$ is a constant and $\epsilon_{e}$ is an error term with the usual assumptions.

The results of estimating equation (14) are reported in column (1) of Table 2. We find a significant positive effect on the pace of adoption for establishments being part of a larger company, suggesting that for establishments that cooperate with other parts of the organisation on different locations the communication possibilities of computers are more important. In addition, we find that the production of different types of output is not strongly related to the pace of within-establishment computer technology adoption, although the production of consumer products seems to be more closely connected to fast adoption than the production of semi-manufactured and other goods. We find a positive and significant relationship for exporting establishments, suggesting that coordination is more important for these establishments. This effect might be the result of communication with foreign customers in the case of producing consumer goods or communication with a foreign-based parent company or other foreign-based parts of the company in the case of producing semi-manufactured products. When we add the covariate with information about foreign ownership we do not find an effect, so it is more likely that this effect is due to communication with foreign customers.

When we turn to measures of competition we find that a higher degree of market competition appears to be unrelated to faster computer technology adoption. However, investigating different types of competition shows that companies competing based on high quality, good services and product advancement adopt computer technology at a higher pace. Competition based on low prices and fast delivery is negatively associated with fast within-establishment computer technology adoption. Other measures of competition do not seem to matter for the rate of computer technology adoption. The estimates for low-price and fast-delivery competition are consistent with the production of relatively 
low-quality products involving a low degree of complexity. Generally the manufacturing of these products does not require an advanced division of labour and the employment of a great many specialists who communicate a lot. The positive association between "highquality" competition and fast computer adoption is an expression of complex products being composed by specialist workers who communicate intensively.

In an effort to investigate complementarities between computer technology and the adoption of other technologies and to distinguish high-tech from low-tech establishments, we include various measures of an establishment's technological advancement such as the extent to which advanced technology is used, the recent adoption of advanced technologies other than computer technologies and R\&D. The second measure is significantly correlated with the rate of computer technology adoption suggesting that communication is more important in establishments adopting more advanced technologies. The coefficient for $\mathrm{R} \& \mathrm{D}$ is negative. To explain these findings we tried interacting the measures of technology with high-quality competition to attempt to determine whether these firms are more effective in the presence of communication. It turns out that the interaction with $R \& D$ is statistically significant related to the rate of computer adoption suggesting that if high-quality competition coincides with $\mathrm{R} \& \mathrm{D}$ communication between workers is more important. The coefficient on R\&D becomes insignificant in such a specification.

The second column in Table 2 reports the estimates of using a dummy variable as the dependent variable. This dummy equals one if the pace of adoption is above average and zero if it is below the average pace of computer adoption. The estimates of doing so are similar although more pronounced. In terms of the magnitude of the coefficients, the estimates in columns (1) and (2) are comparable.

\subsection{The Division of Labour and Computer Technology Adoption}

The next step is to examine the impact of computer technology adoption on changes in the establishment's structure. We examine a number of regression equations applying the biannual changes in computer technology adoption as the exogenous variable. In addition, we distinguish between establishments adopting at an above-average and below-average rate as derived in equation (13). We explore three different sets of regressions. ${ }^{20}$ First,

\footnotetext{
${ }^{20}$ We experimented with splitting the data for different values for $\Gamma$. Although the results change quantitatively, for reasonable values of $\Gamma$ the estimated coefficients remain similar in qualitative terms.
} 
we estimate the change in computer adoption $\triangle C O M P_{e}$ on the indicators of the division of labour presented in Table 1 for all three bi-annual periods between 1990 and 1996:

$$
Y_{e}=C+\alpha_{1} \Delta C O M P_{e}+\epsilon_{e}
$$

where $Y_{e}$ are the different indicators of the division of labour. Secondly, we add the interaction between the change in computer technology adoption and the pace of computer adoption to capture the effect of the pace of adoption on the division of labour:

$$
Y_{e}=C+\alpha_{1} \Delta C O M P_{e}+\alpha_{2} \Delta C O M P_{e} \times \Gamma_{e}+\epsilon_{e}
$$

Finally, we estimate equation (16) by not including the actual value of $\Gamma_{e}$ but a dummy indicating whether the pace of computer technology adoption is above or below average. All equations also include sector and year dummies.

Column (1) of Table 3 reports the results of estimating equation (15). The regressions reveal information about changes in the employment, organisational and pay structure of establishments in the period 1990-1996. The estimated coefficients on the change in computer technology adoption are in most cases statistically significant. The coefficients related to changes in employment structure suggest that larger changes in computer adoption lead to more employment concentration, a higher share of skilled workers and relatively more direct personnel. With respect to the organisational structure of establishments we find that changes in computer technology adoption are correlated with an increasing number of hierarchical layers, smaller teams and smaller establishment size. These findings for the increasing number of layers suggest that establishments faced with an increasing burden of communication try to reduce coordination costs by increasing the number of hierarchies. Smaller team size reflects the generalization of work, while the fall in employment and establishment size could reflect the increase in productivity. Taken together the findings imply that the communication advantages of computer technology are probably generally less important than the productivity improvements. We also find that establishment size is decreasing in computer technology adoption. Together with the increase in the share of skilled workers and the increase in the relative number of direct employees this suggests downsizing at the expense of lower skilled workers. ${ }^{21}$ Finally, we

\footnotetext{
${ }^{21}$ Alternative measures of changes in the share of skilled workers or the ratio of indirect to direct employees yield similar results.
} 
find that there is a marginal change in the difference between the average wages paid to workers in computer adopting establishments. We do find a significant fall in the standard deviation of wages which is consistent with the concentration of employment and the suggestive trend towards downsizing at the expense of lower skilled (and paid) workers in computer adopting establishments.

We finally turn to measure the difference between fast-adopting establishments and establishments taking a more gradual approach to adopting technology by estimating equation (16) for the different measures of the division of labour. From the theory developed above we expect establishments that adopt computers at a gradual rate to decide upon adoption based on (individual workers') productivity benefits, whereas the adoption that takes place at once is related to communication advantages for the establishment as a whole. Our estimated coefficients on changes in computer technology adoption and fast-adopting establishments are presented in column (2) of Table 3. The most striking observation is that the coefficients on the fast-adoption variable are generally of the opposite sign compared to the coefficient on the ordinary adoption variable (in fact all are except for changes in team size). The first set of two regressions explaining changes in the employment structure suggests a negative change for establishments adopting fast compared to the gradual adopters. This result suggests a relative tendency of fast adopting establishments to shift to a more specialised mode of production because they employ a relatively great number of different types of workers, which is consistent with cheaper coordination and lower communication costs. This trade-off between communication costs and specialisation is not present when we review the coefficient on the change in the ratio of indirect to direct employees, since the coefficients are insignificant. Finally, the significant and negative coefficient on the change in the share of skilled workers for fast adopters suggests that lower communication costs go along with downgrading. These estimated coefficients may be interpreted in terms of skill advantages and in that case suggest that lower skilled workers gain more from improved communication possibilities within the firm than higher skilled workers. At the same time, and consistent with the estimates concerning changes in employment structure and the division of labour, the coefficients suggests that the division of tasks to specialised workers results in simple tasks to be performed by relatively lower skilled workers. 
We find that organisational changes play a less prominent role in explaining differences between fast and gradual computer adopting firms. A noteworthy difference between the two sets of establishments is the change in the number of hierarchical layers. Whereas gradual adopting firms increase the number of layers, the net change in layers for fast adopters is negative. Comparison of this result to the results for changes in the employment structure suggests consistency because fast adopting establishments become less concentrated in terms of employment structure, and downgrade in terms of skill requirements.

When we turn to changes in the wage structure we observe that the change in the average wages paid in fast-adopting establishments have been fallen over the period 1990-1996, whereas the changes in the standard deviation of wages are more or less similar to gradual adopters. Again, these results are consistent with the trade-off between communication and specialisation.

Finally, using a dummy for fast adopters versus slow adopters instead of the true value for $\Gamma_{e}$ does not change the results.

\section{Conclusions, Implications, and Future Research}

A simple framework about the division of tasks among workers helps illuminate many aspects of changes in the organisational structure related to the improvements in information and communication technology. The actual division of labour can be seen as the optimal trade-off between the benefits of specialisation and the costs of communication. As computer technology can both improve communication and production, the adoption of this technology is able to change the division of labour in two directions: when communication costs are decreased there will be a tendency towards more specialisation and when production time is decreased there will be more generalisation. The net effect of both possibilities will determine the direction of the division of labour. By distinguishing between firms that adopt because of communication reasons and those that adopt because of reduced production time - based on the specific diffusion pattern - we find a consistent pattern in our data.

An important question is how the changes in the division of labour associated with the adoption of new technologies relate to recent shifts in demand toward skilled labour. 
The model shows that there are potentially several patterns that could explain a skill bias in the demand for labour. Gains in time requirements could be larger for certain tasks as well as for certain workers. Two effects have to be distinguished. First, if the division of labour would be kept constant, workers who gain most or workers who perform tasks that gain most from the adoption of computer technology see the relative demand for their activities being reduced. Secondly, when certain workers gain more in terms of productivity than others, the division of labour will be adjusted to benefit from this productivity advantage. As a consequence, when the reduction in communication time would be the main advantage of computer adoption, increased demand for skilled labour could either be the result of reduced communication costs for simple tasks or a relative gain for skilled workers in communicating. Since the trend is towards generalisation, it is more likely that the skill bias in labour demand has to be found in relation with reduced production time. Hence, either simple tasks have been automated or skilled workers gain more from reduced production time. Taking into account production time and communication simultaneously puts forward a third potential skill bias in the demand for labour. Assuming that communication is a routine task and production is more related to skill (non-routine job activity), a reduction in communication time - even when this is proportional for all workers - would shift demand towards skilled labour. However, because the reduction in production time has been more important in the fact of computer adoption, it can be expected that this has led to downgrading counteracting some of the skill bias in labour demand. Empirically we obtain estimates suggesting that upgrading is only present in the case of a reduction of production time and not in the case of reduced communication costs (it even runs in the opposite direction).

The paper has made three arguments of general interest. First, the impact of computer technology on the division of labour over the past decades reveals how important and time consuming communication between workers must be nowadays. While some time ago physical distances between cities where a major limiting factor for the division of labour (e.g., Smith's quote in footnote 2), nowadays productivity has increased so much that even subtle conversations between co-workers bound the division of labour. Secondly, the paper shows that a more detailed description of the production process, in which these high communication costs are explicitly taken into account, can be a powerful tool to predict 
changes in the division of labour. This approach might be an avenue for future research to understand how firm adjust to changing circumstances. Finally, computer technology has induced a flood of innovations, also in relation to changes in worker organisation. We deliberately looked at how far we could go to explain changes in the division of labour without considering these innovative work practices. Our model and empirical results provide a baseline for researchers who are looking for the effects of successful organisational innovations.

\section{References}

Aghion, P., Caroli, E. and García-Peñalosa, C. (1999). 'Inequality and economic growth: the perspective of the new growth theories', Journal of Economic Literature, vol. 37(4), pp. 1615-60.

Aubert, P., Caroli, E., and Roger, M. (2005). 'New technologies, workplace organisation and the age structure of the workforce: Firm-level evidence', Working Paper, CREST, June 2005.

Autor, D. H., Levy, F., and Murnane, R. J. (2002). 'Upstairs, downstairs: Computers and skills on two floors of a large bank', Industrial 85 Labor Relations Review, vol. 55(3), pp. $432-447$.

Autor, D. H., Levy, F. and Murnane, R. J. (2003). 'The skill content of recent technological change: an empirical exploration', Quarterly Journal of Economics, vol. 118(4), pp. 1279-333.

Baumgardner, J. R. (1988). 'The division of labor, local markets, and worker organization', Journal of Political Economy, vol. 96(3), pp. 509-27.

Becker, G. S. and Murphy, K. M. (1992). 'The division of labor, coordination costs, and knowledge', Quarterly Journal of Economics, vol. 107(4), pp. 1137-60.

Bertschek, I. and Kaiser, U. (2004). 'Productivity effects of organizational change: microeconometric evidence', Management Science, vol. 50(3), pp. 394-404.

Black, S. E. and Lynch, L. M. (2001). 'How to compete: the impact of workplace practices and information technology on productivity', Review of Economics and Statistics, vol. 83(3), pp. 434-45.

Black, S. E. and Lynch, L. M. (2004). 'What's driving the new economy?: The benefits of workplace innovation', Economic Journal, vol. 114(493), pp. F97-F116.

Bolton, P. and Dewatripont, M. (1994). 'The firm as a communication network', Quarterly Journal of Economics, vol. 109(4), pp. 809-39.

Borghans, L. and ter Weel, B. (2002a). 'Do older workers have more trouble using a computer than younger workers?', in (S. Polachek, series ed.), Research in Labor Economics, vol. 21, pp. 139-73.

Borghans, L. and ter Weel, B. (2002b). 'Computers, skills and wages', Working Paper, MERIT, Maastricht University, November 2002.

Borghans, L. and ter Weel, B. (2003). ICT en de Organisatie van Werk in Nederland: Een Studie op Basis van het OSA Arbeidsvraagpanel, OSA Research Report A-197, Tilburg. 
Borghans, L. and ter Weel, B. (2004). 'What happens when agent T gets a computer? The labor market impact of efficient computer adoption', Journal of Economic Behavior E Organization, vol. 54(2), pp. 137-151.

Bresnahan, T. F. (1999). 'Computerisation and wage dispersion: an analytical reinterpretation', Economic Journal, vol. 109(456), pp. F390-F415.

Bresnahan, T. F., Brynjolfsson, E. and Hitt, L. M. (2002). 'Information technology, workplace organization, and the demand for skilled labor: firm level evidence', Quarterly Journal of Economics, vol. 117(1), pp. 339-76.

Bresnahan, T. F. and Greenstein, S. (1996). 'Technical progress and co-invention in computing and in the uses of computers', Brookings Papers on Economic Activity: Microeconomics, pp. 1-77.

Brynjolfsson, E. and Hitt, L. M. (2000). 'Beyond computation: Information technology, organizational transformation and business performance', Journal of Economic Perspectives, vol. 14(4), pp. 23-48.

Brynjolfsson, E. and Hitt, L. M. (2003). 'Computing productivity: firm level evidence', Review of Economics and Statistics, vol. 85(4), pp. 793-808.

Caroli, E. and Van Reenen, J. (2001). 'Skill-biased organizational change? Evidence from a panel of British and French establishments', Quarterly Journal of Economics, vol. 116(4), pp. 1449-92.

Fernandez, R. M. (2001). 'Skill-biased technological change and wage inequality: Evidence from a plant retooling', American Journal of Sociology, vol. 107(2), pp. 273-320.

Friedberg, L. (2003). 'The impact of technological change on older workers: Evidence from data on computer use', Industrial and Labor Relations Review, vol. 56(3), pp. 51129.

Ichniowski, C., Shaw, K. and Gant, J. (2003). 'Working smarter by working together: Connective capital in the workplace', Mimeo, Stanford University.

Ichniowski, C., Shaw, K. and Prennushi, G. (1997). 'The effects of human resource management practices on productivity', American Economic Review, vol. 87(3), pp. 291313.

Kremer, M. (1993). 'The o-ring theory of economic development', Quarterly Journal of Economics, vol. 108(3), pp. 551-75.

Levy, F. and Murnane, R. J. (1996). 'With what skills are computers complements?', American Economic Review, vol. 86(2), pp. 258-262.

Lindbeck, A. and Snower, D. J. (2000). 'Multitask learning and the reorganization of work: from tayloristic to holistic organization', Journal of Labor Economics, vol. 18(3), pp. 353-76.

Milgrom, P. and Roberts, J. (1990). 'The economics of modern manufacturing: technology, strategy, and organization', American Economic Review, vol. 80(3), pp. 511-28.

Osterman, P. (1994). 'How common in workplace transformation and who adopts it?', Industrial and Labor Relations Review, vol. 47(1), pp. 173-88.

Osterman, P. (2000). 'Work reorganization in an era of restructuring: trends in diffusion and effects on employee welfare', Industrial and Labor Relations Review, vol. 53(2), pp. 179-96.

Radner, R. (1993). 'The organization of decentralized information processing', Econometrica, vol. 61(5), pp. 1109-46.

Rosen, S. (1978). 'Substitution and the division of labour', Economica, vol. 45(179), pp. $235-50$. 
Rosen, S. (1983). 'Specialization and human capital', Journal of Labor Economics, vol. 1(1), pp. 43-9.

Sah, R. and Stiglitz, J. E. (1985). 'Human fallibility and economic organizations', American Economic Review, vol. 75(2), pp. 292-7.

Smith, A. (1776). An Inquiry into the Nature and Causes of the Wealth of Nations.

Sobel, J. (1992). 'How to count to one thousand', Economic Journal, vol. 102(410), pp. 1-8.

Spitz, A. (2003). 'IT capital, job content and educational attainment', Discussion Paper no. 03-04, ZEW, Mannheim, January 2003.

Weinberg, B. A. (2005). 'Experience and technology adoption', Working Paper, Ohio State University, April 2005. 
Figure 1

Time Needed for Production and Communication for Five Types of Workers
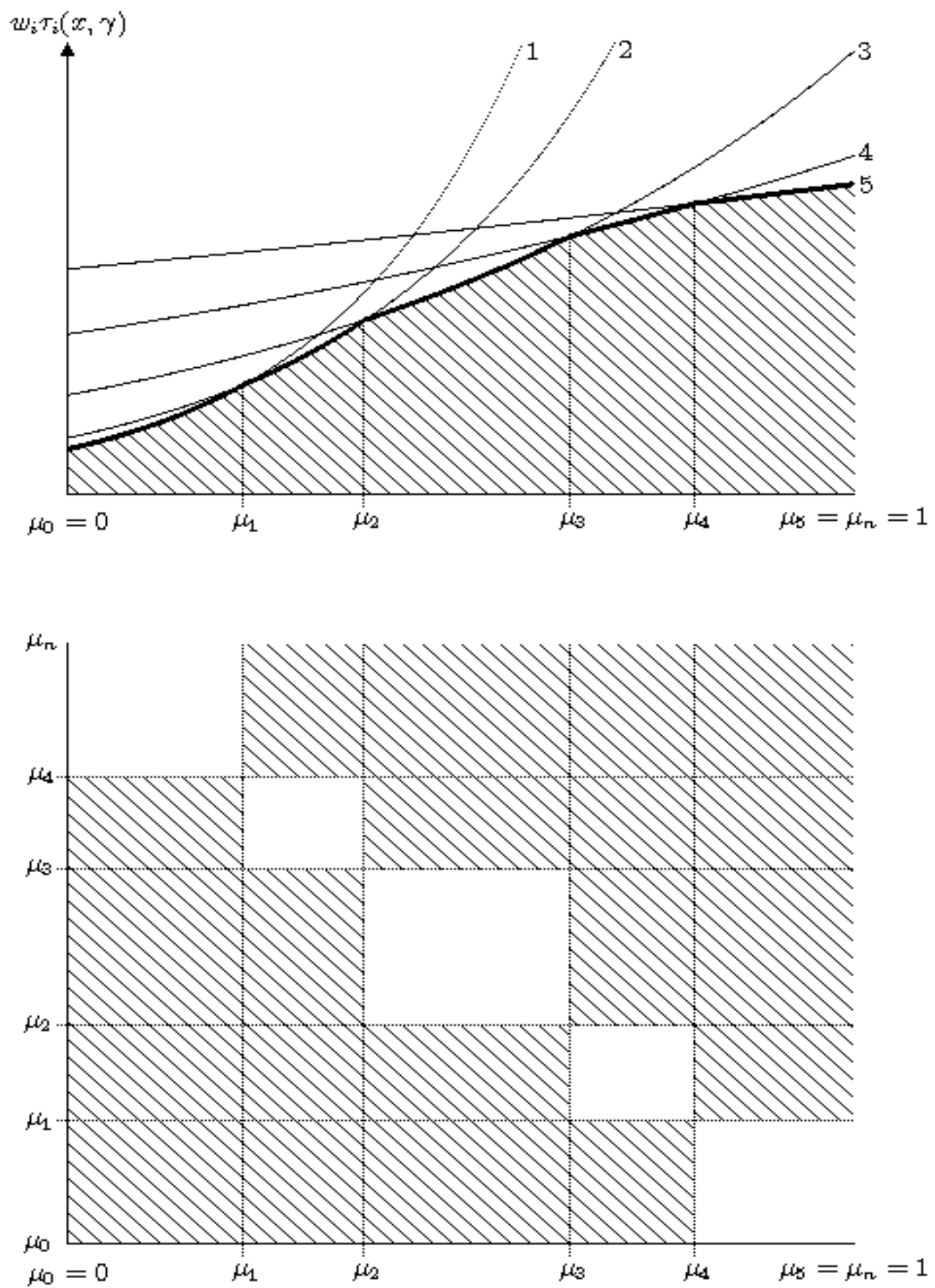

Production and communication costs for firm with tasks uniformly distributed on the interval [0,1], with five types of workers $(i=1, \ldots, 5)$, with $\tau_{i}(x, 1)=e^{a_{i} x}, w_{2}=1.25 w_{1}, w_{3}=2.20 w_{1}, w_{4}=3.55 w_{1}, w_{5}=5.00 w_{1}$, and $a_{1}=4$, $a_{2}=3, a_{3}=1.5, a_{4}=0.75, a_{5}=0.32$. Dashed lines represent the optimal division of labour when communication costs are not taken into account. 
Figure 2

Numerical Example of the Optimal Division of Labour when Communication Costs Increase

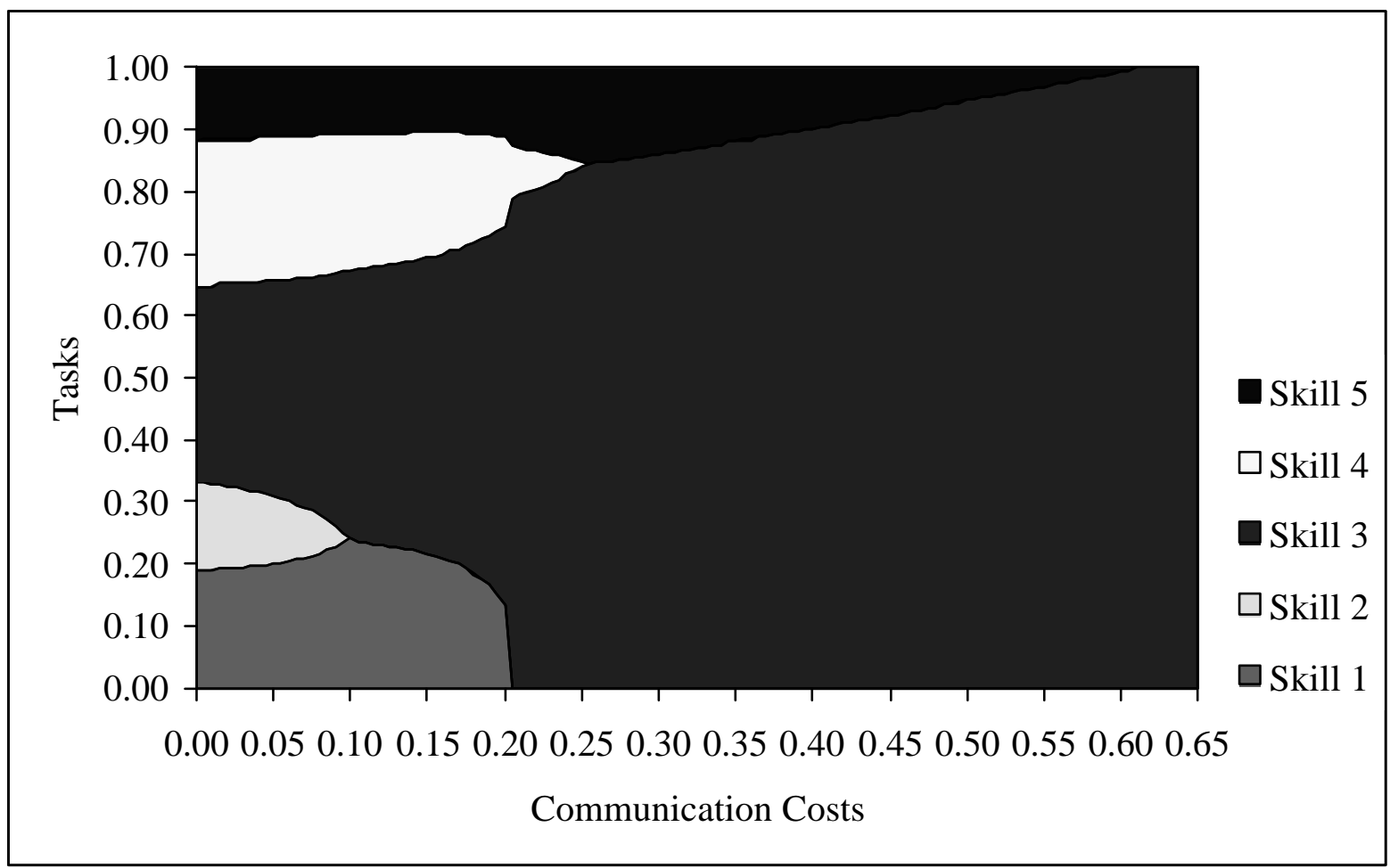

Simulations are based on 250 tasks $(x)$, uniformly distributed on the interval [0,1], with five types of workers $(i=1, \ldots, 5)$, with $\tau_{i}(x, 1)=e^{a_{i} x}, w_{2}=1.25 w_{1}, w_{3}=2.20 w_{1}, w_{4}=3.55 w_{1}, w_{5}=5.00 w_{1}$, and $a_{1}=4, a_{2}=3, a_{3}=1.5$, $a_{4}=0.75, a_{5}=0.32$. 
Figure 3

A: Biannual Computer Adoption Rates

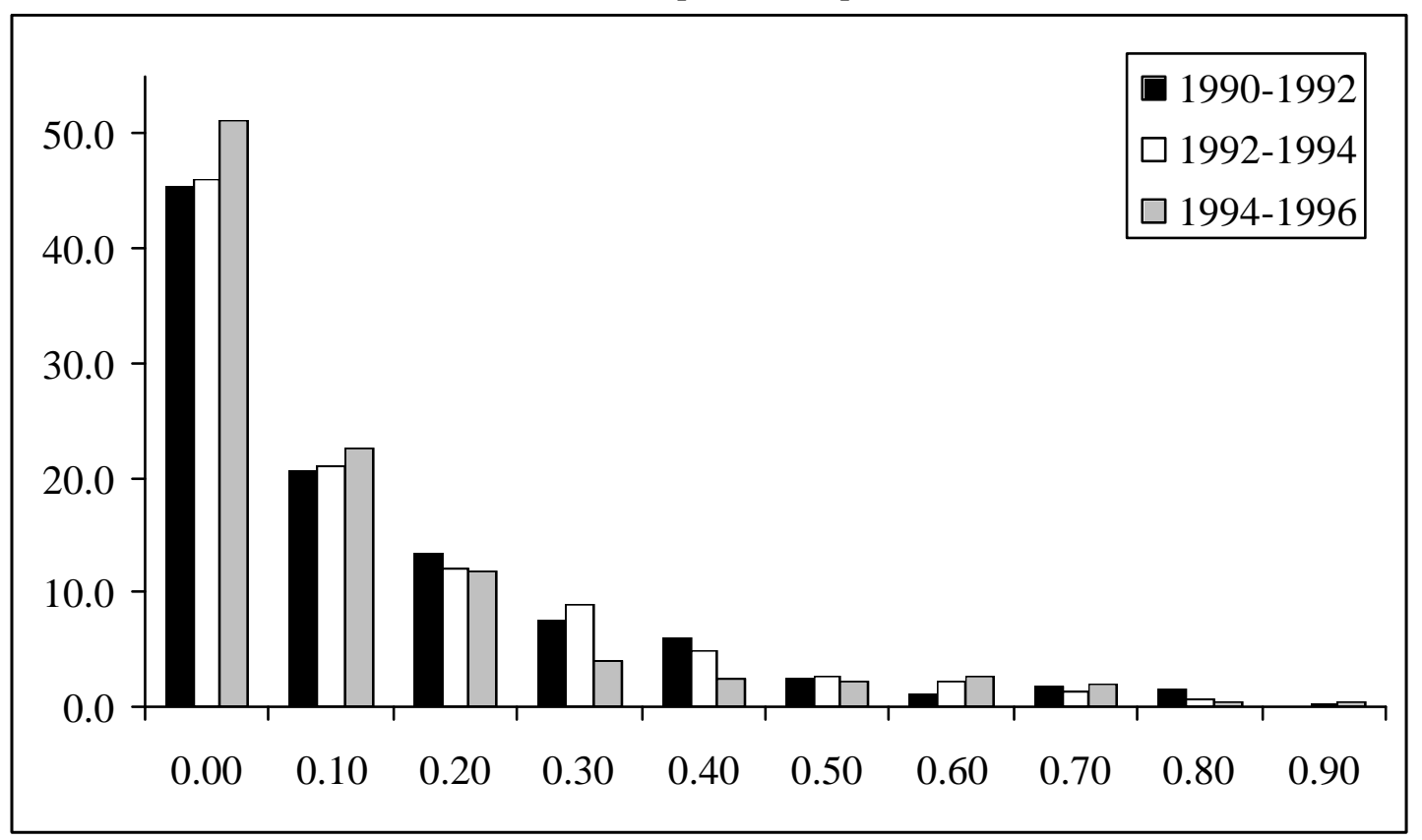

B: The Distribution of $\Gamma$

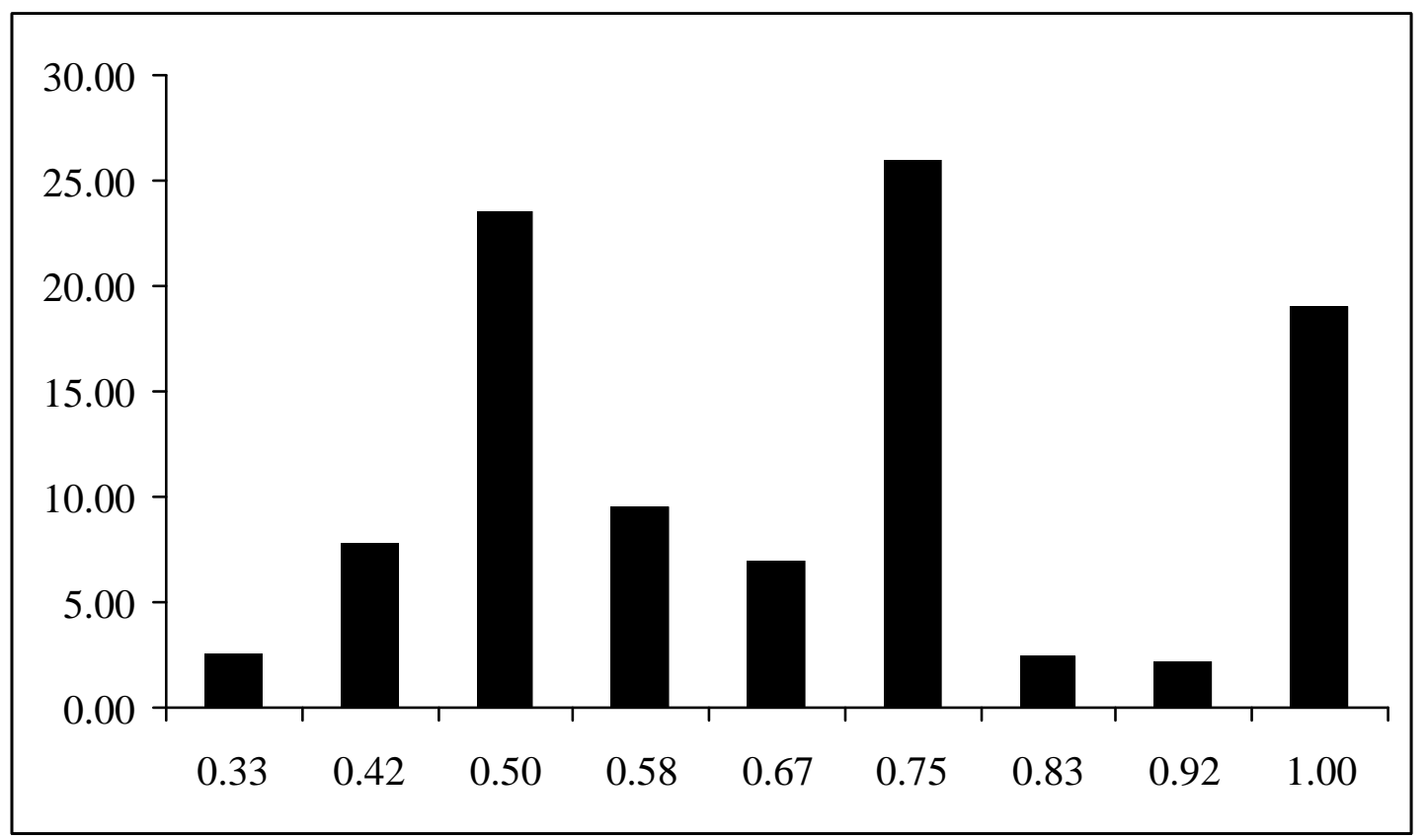

The number of observations equals 2,096. 
Table 1

Descriptive Statistics

\begin{tabular}{llc}
\hline & Mean & St.dev. \\
\hline Computer technology & & 0.223 \\
Change in computer technology use & 0.051 & 0.192 \\
$\Gamma$ & 0.723 & 0.110 \\
Employment structure & & 0.187 \\
Change in employment concentration & 0.023 & 3.373 \\
Change in the share of skilled workers & 0.022 & -0.316 \\
Change in the ratio indirect/direct employees & & 0.871 \\
& & 0.215 \\
Organisational structure & -0.012 & 0.379 \\
Change in the number of hierarchical layers & 0.009 & \\
Change in log team size & 0.030 & \\
Change in log establishment size & & \\
& & 0.133 \\
Wages & & 0.446 \\
Change in log average wages & 0.066 & \\
\hline
\end{tabular}

N 2,096

a An establishment's employment concentration is measured as the sum of squared terms of the share of four types of workers categorised by level of education. 
Table 2

The Determinants of Fast Within-Establishment Computer Technology Diffusion

\begin{tabular}{|c|c|c|c|c|c|c|}
\hline \multirow{2}{*}{ Ownership } & \multicolumn{3}{|c|}{$\begin{array}{c}1 \\
\Gamma \text { (continuous) } \\
\end{array}$} & \multicolumn{3}{|c|}{$\begin{array}{c}2 \\
\Gamma(0,1) \\
\end{array}$} \\
\hline & & & & & & \\
\hline Management owns establishment & 0.005 & $(0.013)$ & {$[0.010]$} & 0.040 & $(0.033)$ & [0.030] \\
\hline Establishment is part of a larger enterprise & 0.030 & $(0.010)$ & {$[0.078]$} & 0.055 & $(0.026)$ & {$[0.056]$} \\
\hline \multicolumn{7}{|l|}{ Production } \\
\hline Production of consumer products & 0.014 & $(0.010)$ & [0.034] & 0.016 & $(0.027)$ & [0.015] \\
\hline Production of semi-manufactured products & 0.016 & $(0.026)$ & {$[0.014]$} & 0.016 & $(0.067)$ & {$[0.006]$} \\
\hline Production of other products & & reference & & & reference & \\
\hline Part of the production is exported & 0.049 & $(0.012)$ & {$[0.125]$} & 0.082 & $(0.031)$ & [0.079] \\
\hline Degree of market competition & -0.005 & $(0.007)$ & [-0.024] & -0.045 & $(0.018)$ & {$[-0.077]$} \\
\hline \multicolumn{7}{|l|}{ Competition } \\
\hline Competition based on low price & -0.199 & $(0.034)$ & {$[-0.147]$} & -0.763 & $(0.088)$ & {$[-0.217]$} \\
\hline Competition based on fast delivery & -0.211 & $(0.037)$ & {$[-0.161]$} & -0.463 & $(0.097)$ & {$[-0.136]$} \\
\hline Competition based on high quality & 0.170 & $(0.033)$ & {$[0.151]$} & 0.432 & $(0.086)$ & [0.148] \\
\hline Competition based on good service & 0.090 & $(0.032)$ & {$[0.080]$} & 0.205 & $(0.084)$ & {$[0.070]$} \\
\hline Competition based on branding & 0.041 & $(0.037)$ & {$[0.030]$} & 0.049 & $(0.096)$ & {$[0.014]$} \\
\hline Competition based on product advancement & 0.269 & $(0.103)$ & {$[0.061]$} & 0.267 & $(0.270)$ & {$[0.023]$} \\
\hline Competition based on tailor-mades & -0.024 & $(0.069)$ & {$[-0.008]$} & -0.014 & $(0.179)$ & {$[-0.002]$} \\
\hline Competition based on high-fashion products & 0.029 & $(0.033)$ & {$[0.022]$} & 0.058 & $(0.086)$ & {$[-0.016]$} \\
\hline \multicolumn{7}{|l|}{ Technology } \\
\hline \multirow{2}{*}{$\begin{array}{l}\text { Extent to which advanced technology is used } \\
\text { Recent adoption of advanced technologies } \\
\text { (other than computer technologies) }\end{array}$} & -0.003 & $(0.005)$ & {$[-0.012]$} & -0.027 & $(0.014)$ & {$[-0.045]$} \\
\hline & 0.030 & $(0.010)$ & [0.076] & 0.055 & $(0.026)$ & [0.054] \\
\hline $\begin{array}{l}\text { Research and development } \\
\text { (involvement in both internal and } \\
\text { external projects) }\end{array}$ & -0.024 & $(0.011)$ & {$[-0.058]$} & -0.103 & $(0.028)$ & {$[-0.096]$} \\
\hline Intercept & 0.699 & $(0.014)$ & & 0.592 & $(0.036)$ & \\
\hline Adjusted $\mathrm{R}^{2}$ & 0.112 & & & 0.106 & & \\
\hline$N$ & 2,096 & & & 2,096 & & \\
\hline
\end{tabular}

Robust standard errors are reported in brackets and predicted effects in square brackets. Regressions are weighted by establishment size. 
Table 3

The Impact of Computer Technology Adoption on an Establishment's Employment, Organisational and Pay Structure

\begin{tabular}{|c|c|c|c|c|c|}
\hline & \multirow{2}{*}{$\begin{array}{c}1 \\
\Delta C O M P\end{array}$} & \multicolumn{2}{|c|}{2} & \multicolumn{2}{|c|}{3} \\
\hline & & $\triangle C O M P$ & $\begin{array}{l}\triangle C O M P \times \Gamma \\
(\Gamma \text { continuous })\end{array}$ & $\triangle C O M P$ & $\begin{array}{c}\Delta C O M P \times \Gamma \\
(\Gamma(0,1))\end{array}$ \\
\hline Change in employment & 0.041 & 0.117 & -0.103 & 0.053 & -0.036 \\
\hline \multirow[t]{2}{*}{ concentration } & $(0.010)$ & $(0.053)$ & $(0.069)$ & $(0.012)$ & $(0.018)$ \\
\hline & {$[0.090]$} & {$[0.260]$} & {$[-0.173]$} & {$[0.117]$} & {$[-0.048]$} \\
\hline Change in the share & 0.035 & 0.289 & -0.340 & 0.069 & -0.097 \\
\hline \multirow[t]{2}{*}{ of skilled workers } & $(0.017)$ & $(0.088)$ & $(0.115)$ & $(0.020)$ & $(0.034)$ \\
\hline & {$[0.046]$} & {$[0.384]$} & {$[-0.344]$} & {$[0.092]$} & {$[-0.079]$} \\
\hline Change in the ratio & -0.375 & -1.289 & 1.166 & -0.612 & 0.523 \\
\hline \multirow[t]{2}{*}{ indirect/direct employees } & $(0.152)$ & $(0.721)$ & $(0.898)$ & $(0.205)$ & $(0.305)$ \\
\hline & {$[-0.048]$} & {$[-0.165]$} & {$[0.120]$} & {$[-0.079]$} & {$[0.045]$} \\
\hline Change in the number & 0.183 & 1.397 & -1.569 & 0.553 & -0.852 \\
\hline \multirow[t]{2}{*}{ of hierarchical layers } & $(0.083)$ & $(0.448)$ & $(0.569)$ & $(0.108)$ & $(0.163)$ \\
\hline & {$[0.044]$} & [0.337] & [-0.298] & [0.134] & {$[-0.137]$} \\
\hline \multirow[t]{3}{*}{ Change in log team size } & -0.188 & -0.083 & -0.136 & -0.142 & -0.016 \\
\hline & $(0.035)$ & $(0.183)$ & $(0.233)$ & $(0.046)$ & $(0.067)$ \\
\hline & [-0.089] & {$[-0.040]$} & {$[-0.050]$} & {$[-0.067]$} & {$[-0.033]$} \\
\hline \multirow{3}{*}{$\begin{array}{l}\text { Change in log } \\
\text { establishment size }\end{array}$} & -0.208 & -0.382 & 0.232 & -0.262 & 0.121 \\
\hline & $(0.027)$ & $(0.142)$ & $(0.185)$ & $(0.036)$ & $(0.054)$ \\
\hline & {$[-0.124]$} & {$[-0.227]$} & {$[0.105]$} & {$[-0.155]$} & {$[0.048]$} \\
\hline Change in log & 0.018 & 0.117 & -0.142 & 0.027 & -0.049 \\
\hline \multirow[t]{2}{*}{ average wages } & $(0.012)$ & $(0.065)$ & $(0.084)$ & $(0.014)$ & $(0.025)$ \\
\hline & {$[0.030]$} & {$[0.218]$} & {$[-0.203]$} & {$[0.052]$} & {$[-0.057]$} \\
\hline \multirow{3}{*}{$\begin{array}{l}\text { Change in standard deviation } \\
\text { of log wages }\end{array}$} & -0.157 & 0.022 & -0.238 & -0.141 & -0.044 \\
\hline & $(0.037)$ & $(0.191)$ & $(0.250)$ & $(0.046)$ & $(0.074)$ \\
\hline & {$[-0.098]$} & {$[0.014]$} & {$[-0.114]$} & {$[-0.088]$} & {$[-0.017]$} \\
\hline
\end{tabular}

Robust standard errors are reported in brackets and predicted effects in square brackets. All regressions are weighted by establishment size, except for the regre ssions in which establishment size is the dependent variable. All regressions include time and sector dummies. The number of observations equals $2,096$. 